\title{
ALGUMAS INCURSÕES EM TRABALHOS PRODUZIDOS NO CAMPO DA HISTÓRIA DA LEITURA NO BRASIL
}

\author{
Raimunda Dias DUARTE ${ }^{1}$ \\ Universidade Federal do Pará \\ rayduart@ufpa.br \\ Laura Maria Silva Araújo ALVES ${ }^{2}$ \\ Universidade Federal do Pará \\ laura_alves@uol.com.br
}

Resumo: Neste trabalho é feito um breve levantamento de teses desenvolvidas sobre a 'história das práticas da leitura no Brasil', referente ao período de 2003 a 2010, para investigar como esse objeto vem sendo tratado do ponto de vista teóricometodológico. O procedimento metodológico consistiu em um levantamento no banco de teses da CAPES e de três Instituições de Ensino Superior (IES) de teses vinculadas a programas de pós-graduação que desenvolvem pesquisas dentro da temática escolhida. Os resultados da investigação revelam que a abordagem teóricometodológica que orienta as pesquisas é a história cultural, principalmente os trabalhos introduzidos por Roger Chartier, com foco metodológico na pesquisa documental. Os dados revelam também que, das IES investigadas, esse tipo de abordagem teóricometodológica predomina na UNICAMP, em razão de essa instituição desenvolver projeto de grande envergadura voltado para a história da leitura.

Palavras-chave: História Cultural. Práticas da leitura. História da leitura.

Abstract: This paper made a brief survey of the theories developed on the "history of reading practices in Brazil', covering the period 2003-2010, to investigate how this object has been treated from the standpoint of theoretical and methodological. The methodological procedure consisted of a survey in the CAPES thesis database and three Higher Education Institutions (HEIs) of thesis linked to postgraduate programs that develop research within the chosen theme. Research results show that the theoretical and methodological approach that guides the research is cultural history, especially the work introduced by Roger Chartier, focusing on documentary research methodology. The data also reveal that the HEIs investigated, such theoretical and

\footnotetext{
${ }^{1}$ Doutoranda do Programa de Pós-Graduação em Educação/Instituto de Ciências da Educação da Universidade Federal do Pará/ICED/UFPA, na linha de pesquisa Educação, Cultura e Sociedade. Professora Assistente II de Língua Portuguesa e Linguística da Faculdade de Ciências da Linguagem/FACL/Campus Universitário de Abaetetuba/ UFPA.

${ }^{2}$ Docente do PPGED/ICED/UFPA; orientadora.
} 
methodological approach predominates at UNICAMP, because of this institution to develop large-scale project focused on the history of reading.

Keywords: Cultural History. Practice reading. History of reading

\section{Introdução}

Com o objetivo de investigar como a história das práticas da leitura no Brasil vem sendo tratada do ponto de vista teórico-metodológico, este estudo faz um breve levantamento dos trabalhos realizados, no período de 2003 a 2010, sobre a temática em questão. Privilegiou-se as teses vinculadas aos programas de pós-graduação em Educação (embora $20 \%$ dos trabalhos encontrados sejam provenientes de outras áreas do conhecimento), com conceitos 5, 6 e 7, emitidos pela Coordenação de Aperfeiçoamento de Pessoal de Ensino Superior (CAPES). A escolha do objeto se deu em razão de o projeto de tese da autora ter tido como proposta inicial analisar as práticas da leitura em grupos escolares no Estado do Pará’3.

O trabalho está organizado da seguinte maneira: em primeiro lugar, descreve-se o campo de coleta dos dados: programas de pósgraduação, bancos de teses consultados e critérios para coleta das teses. Em seguida, procede-se à análise das teses da seguinte maneira: apresentase, em primeiro lugar, um quadro que descreve cada uma das teses, informando título, autor, ano de publicação, objeto e pressupostos teórico-metodológicos; depois, faz-se uma análise teórico-metodológica das teses, observando-se o foco metodológico e a orientação teórica que sustenta os trabalhos. Nessa etapa do trabalho, também são analisadas as teses das instituições onde houve um maior quantitativo de trabalhos e os três trabalhos diretamente relacionados ao objeto inicial de pesquisa da autora deste estudo.

\section{A coleta dos dados}

Para a realização da pesquisa, foi consultado o banco de teses da CAPES, da UNICAMP, da UFMG e da UNESP/MARÍLIA. Dos 21

\footnotetext{
${ }^{3}$ No período em que a investigação foi realizada (1 ${ }^{\circ}$. Semestre/2011), a autora, ainda no primeiro semestre do Curso de Doutorado, não estava com o seu objeto totalmente definido, mas sabia, contudo, que iria trabalhar com a leitura. Hoje, com suas investigações mais consolidadas, definiu como objeto de pesquisa 'livros escolares de leitura do início do século XX'.
} 
programas de pós-graduação em educação (ED) com conceitos 5, 6 e 7, recomendados pela CAPES, 7 interessam para esta pesquisa, em razão de conterem trabalhos sobre o tema pesquisado. Além desses, foram encontrados trabalhos relevantes em programas de pós-graduação em história (HIST) e linguística (LING), conforme se observa no quadro 1, abaixo:

Quadro 1 - Programas de pós-graduação

\begin{tabular}{|c|c|c|c|}
\hline \multirow{3}{*}{ REGIÃO } & PPG/IFES & $\begin{array}{c}\text { CONCEITO } \\
\text { CAPES }\end{array}$ & $\begin{array}{c}\text { NÚMERO DE } \\
\text { TRABALHOS } \\
\text { 2003-2010 }\end{array}$ \\
\hline Nordeste & UFRN/ED & 5 & 01 \\
\hline \multirow{5}{*}{ Sudeste } & UFMG/ED & 7 & 03 \\
\cline { 2 - 4 } & PUC-SP/ED & 5 & 02 \\
& PUC-SP/HIST & 5 & 01 \\
& PUC-SP/LING & 5 & 01 \\
\cline { 2 - 4 } & UNESP/MAR/ED & 5 & 03 \\
\cline { 2 - 4 } & UNICAMP/ED & 5 & 04 \\
\cline { 2 - 4 } & UNICAMP/LING & 7 & 01 \\
\hline & USP/ED & 6 & 02 \\
& USP/HIST & 7 & 01 \\
\hline \multirow{5}{*}{ UFES } & 5 & 01 \\
\hline
\end{tabular}

Fonte: CAPES/abril de 2011

No banco de teses da CAPES, inicialmente, foram encontradas 1254 teses com o descritor 'história da leitura', vinculadas a diversos programas de pós-graduação. Com a necessidade de delimitar melhor os dados, usou-se o descritor 'história das práticas da leitura', por meio do qual foram encontradas 348 teses. Para filtrar ainda mais a pesquisa, levou-se em consideração o ano em que a tese foi publicada (de 2003 a 2010), o tema do trabalho e o programa ao qual a pesquisa estava vinculada; neste caso, os programas de pós-graduação com conceitos 5,6 e 7. 
Nessa etapa da pesquisa, foi feita uma análise minuciosa, lendose, um por um, os resumos das teses para selecionar quais delas se alinhavam com o objeto pesquisado e descartando-se os trabalhos cuja data de publicação não compreendia o período estabelecido.

Além do banco de teses da CAPES, foram consultados também os bancos de teses da UNICAMP, da UFMG e da UNESP/MARÍLIA. Como resultado dessas pesquisas, foram encontradas 20 teses. Dessas, 16 são de programas de pós-graduação em educação, 2 de programas de pós-graduação em linguística e 2 de programas de pós-graduação em história social. Evidentemente, a pesquisa não é conclusiva, uma vez que o banco de teses da CAPES não está atualizado, considerando que não há nenhuma tese publicada em $2010^{4}$, embora, pela exiguidade do tempo ${ }^{5}$, só tenha sido consultado o banco de teses de três instituições, conforme visto acima, cuja pesquisa não fora exaustiva.

\section{A análise dos dados}

\subsection{Considerações gerais}

As teses foram analisadas de acordo com os dados descritos no quadro 2, abaixo. Para chegar a esses resultados, leu-se, em primeiro lugar, o resumo dos trabalhos. Quando estes se mostravam inconsistentes - o que aconteceu na maioria dos trabalhos analisados -, recorria-se à introdução e, quando necessário, aos pressupostos teórico-metodológicos das teses. Contudo, houve casos em que não foi possível o acesso ao trabalho completo. Desta forma, não foi informado o referencial teórico de quatro trabalhos. ${ }^{6}$

\footnotetext{
${ }^{4}$ As duas teses referentes ao ano de 2010 foram encontradas no banco de teses da UNESP

${ }^{5}$ A investigação foi realizada como exigência da disciplina Seminário de Tese I, ministrada pela Profa. Dra. Josenilda Maués, docente do Programa de Pós-Graduação em Educação da UFPA.

${ }^{6}$ Ver teses 6, 7, 11 e 17.
} 
Quadro 2-descrição das teses

\begin{tabular}{|c|c|c|c|}
\hline PPGED & $\begin{array}{c}\text { TÍTULO/ANO } \\
\text { AUTOR/A }\end{array}$ & ОВЈЕТО & $\begin{array}{c}\text { ENFOQUE } \\
\text { TEÓRICO- } \\
\text { METODOLÓGICO }\end{array}$ \\
\hline UFRN & $\begin{array}{l}\text { 1. Leitura e formação do- } \\
\text { cente: a trajetória da prática } \\
\text { da leitura de alunos(as) do } \\
\text { Curso de Letras - } 2005 \\
\text { Araceli Sobreira }\end{array}$ & $\begin{array}{l}\text { Prática da leitura } \\
\text { de alunos(as) do } \\
\text { curso de Letras }\end{array}$ & $\begin{array}{l}\text { Josso; Nóvoa; } \\
\text { Bakhtin; Barton, } \\
\text { Kramer, Larrosa e } \\
\text { Pennac; } \\
\text { Pesquisa-ação }\end{array}$ \\
\hline \multirow{3}{*}{ UFMG } & $\begin{array}{l}\text { 2. A missão "desanalfabe- } \\
\text { tizadora" do jornal Gazeta } \\
\text { do Norte, em Montes Claros } \\
(1918-1938)-2008 \\
\text { Geisa Magela Veloso }\end{array}$ & $\begin{array}{l}\text { Práticas culturais } \\
\text { produzidas em } \\
\text { Montes Claros- } \\
\text { MG }\end{array}$ & $\begin{array}{l}\text { Chartier; Elias, } \\
\text { Baudrillard; Le Goff. } \\
\text { Pesquisa documental }\end{array}$ \\
\hline & $\begin{array}{l}\text { 3. Cultura escolar, práti- } \\
\text { cas e produção dos grupos } \\
\text { escolares em MG (1891- } \\
\text { 1918)-2004 } \\
\text { Irlen Antônio Gonçalves }\end{array}$ & $\begin{array}{l}\text { Práticas e } \\
\text { produções de } \\
\text { grupos escolares }\end{array}$ & $\begin{array}{l}\text { Michel de Certeau;- } \\
\text { Viñao Frago; } \\
\text { Dominique Julia e } \\
\text { Faria Filho } \\
\text { Pesquisa documental }\end{array}$ \\
\hline & $\begin{array}{l}\text { 4. Escolarização da leitu- } \\
\text { ra no ensino graduado em } \\
\text { Minas Gerais (1906-1930) } \\
\text { - } 2003 \\
\text { Karine Klinke }\end{array}$ & $\begin{array}{l}\text { Práticas de } \\
\text { leitura no ensino } \\
\text { graduado }\end{array}$ & $\begin{array}{l}\text { Dominique Julia, } \\
\text { Chervel, Jean } \\
\text { Hébrard; Roger } \\
\text { Chartier } \\
\text { Pesquisa documental }\end{array}$ \\
\hline
\end{tabular}




\begin{tabular}{|c|c|c|c|}
\hline \multirow{4}{*}{ PUC-SP } & $\begin{array}{l}\text { 5. O que é leitura?: uma } \\
\text { investigação interdisciplinar } \\
\text { - } 2009 \\
\text { Rosangela Almeida Valério }\end{array}$ & Projeto de leitura & $\begin{array}{l}\text { Roland Barthes, } \\
\text { Cavallo e Chartier, } \\
\text { Paulo Freire, Piaget, } \\
\text { Smolka, Vygotsky } \\
\text { Fazenda, Klein; } \\
\text { Pesquisa } \\
\text { hermenêutico- } \\
\text { fenomenológica }\end{array}$ \\
\hline & $\begin{array}{l}\text { 6. Cartilhas: um para- } \\
\text { digma didático-linguístico } \\
\text { da alfabetização no Brasil } \\
-2005 \\
\text { Rossana Regina Guimarães } \\
\text { Ramos }\end{array}$ & $\begin{array}{l}\text { Cartilhas utiliza- } \\
\text { das na alfabetiza- } \\
\text { ção no Brasil }\end{array}$ & $\begin{array}{l}\text { Não foi possível listar } \\
\text { o referencial teórico } \\
\text { Pesquisa documental }\end{array}$ \\
\hline & $\begin{array}{l}\text { 7. Entre a Tinta e o Papel: } \\
\text { Memórias de Leituras e Es- } \\
\text { critas Femininas na Bahia } \\
(1870-1920)-2004 \\
\begin{array}{l}\text { Márcia Maria da Silva } \\
\text { Barreiros Leite }\end{array}\end{array}$ & $\begin{array}{l}\text { Práticas cultu- } \\
\text { rais de leitura e } \\
\text { escrita de mu- } \\
\text { lheres de elite da } \\
\text { Bahia }\end{array}$ & $\begin{array}{l}\text { Não foi possível listar } \\
\text { o referencial teórico } \\
\text { Pesquisa documental }\end{array}$ \\
\hline & $\begin{array}{l}\text { 8. Uma leitura dos livros } \\
\text { de leitura da Escola Ameri- } \\
\text { cana em São Paulo (1889- } \\
\text { 1933) - } 2003 \\
\text { Shirley Puccia Laguna. }\end{array}$ & Livros de leitura & $\begin{array}{l}\text { Roger Chartier } \\
\text { Pesquisa documental }\end{array}$ \\
\hline
\end{tabular}




\begin{tabular}{|c|c|c|c|}
\hline \multirow{3}{*}{$\begin{array}{c}\text { UNESP/ } \\
\text { MAR }\end{array}$} & $\begin{array}{l}\text { 9. A leitura como prática } \\
\text { cultural e o processo de } \\
\text { escolarização: as vozes das } \\
\text { crianças }-2010 \\
\text { Fabiana Rodrigues Cruvinel }\end{array}$ & $\begin{array}{l}\text { As relações en- } \\
\text { tre o processo de } \\
\text { escolarização e o } \\
\text { processo de apro- } \\
\text { priação da leitura } \\
\text { sob a perspectiva } \\
\text { das crianças em } \\
\text { início da vida es- } \\
\text { colar }\end{array}$ & $\begin{array}{l}\text { Vigotski; Bakhtin } \\
\text { Estudo de caso } \\
\text { Etnográfico }\end{array}$ \\
\hline & $\begin{array}{l}\text { 10.Entre gestos e práticas: } \\
\text { Leitura de mães, professoras } \\
\text { e meninas de um centro de } \\
\text { referência Down - } 2010 \\
\text { Ana Maria Esteves } \\
\text { Bortolanza }\end{array}$ & $\begin{array}{l}\text { Práticas de leitura } \\
\text { de três mães, três } \\
\text { professoras e três } \\
\text { meninas de um } \\
\text { Centro de Refe- } \\
\text { rência Down }\end{array}$ & $\begin{array}{l}\text { Perrot; Certeau, } \\
\text { Fischer, Manguel, } \\
\text { Chartier e Cavallo; } \\
\text { Vygotsky, Bakhtin } \\
\text { Viñao Frago e Bajard } \\
\text { Estudo de caso } \\
\text { etnográfico }\end{array}$ \\
\hline & $\begin{array}{l}\text { 11. Ler e escrever: muito } \\
\text { prazer, lembranças, histórias } \\
\text { e memórias de professoras } \\
\text { de Rio - } 2009 \\
\text { Elisabete Carvalho de Melo. }\end{array}$ & $\begin{array}{l}\text { Expe riências } \\
\text { pessoais e profis- } \\
\text { sionais com lei- } \\
\text { tura e escrita }\end{array}$ & $\begin{array}{l}\text { Não foi possível listar } \\
\text { o referencial teórico } \\
\text { Pesquisa } \\
\text { autobiográfica }\end{array}$ \\
\hline
\end{tabular}




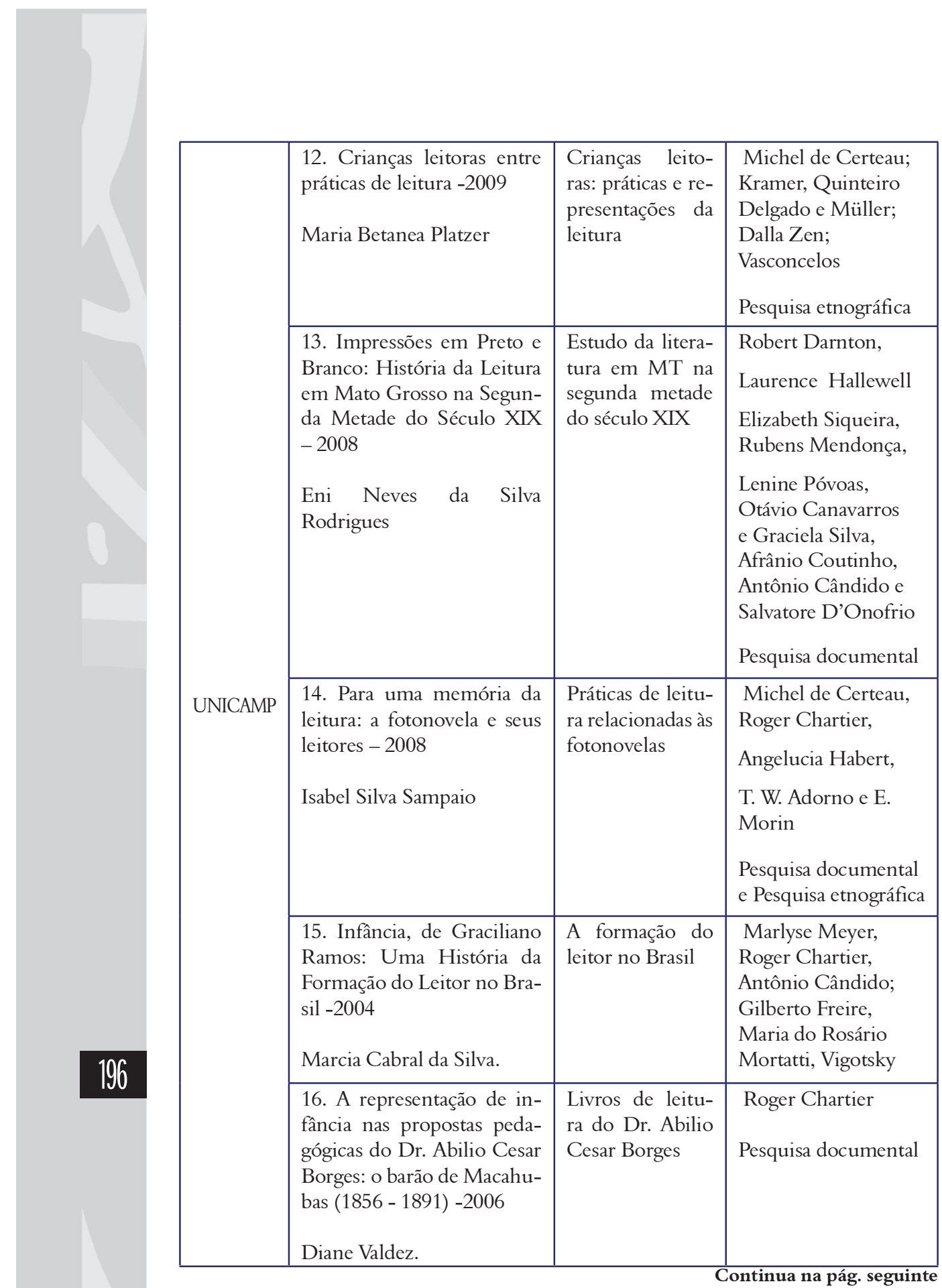




\begin{tabular}{|c|c|c|c|}
\hline \multirow{3}{*}{ USP } & $\begin{array}{l}\text { 17. Os paradeiros da escola } \\
\text { primária pública paulistana } \\
\text { 1922-2002: representações } \\
\text { sobre o tempo, os espaços e } \\
\text { os métodos - } 2005 \\
\text { Ingrid Hötte Ambrogi }\end{array}$ & $\begin{array}{l}\text { História da esco- } \\
\text { la primária pú- } \\
\text { blica paulistana }\end{array}$ & $\begin{array}{l}\text { Não foi possível } \\
\text { listar o referencial } \\
\text { teórico } \\
\text { Pesquisa documental }\end{array}$ \\
\hline & $\begin{array}{l}\text { 18. Composição de textos } \\
\text { na escola brasileira: em bus- } \\
\text { ca de uma história. Do Ra- } \\
\text { tio Studiorum aos manuais } \\
\text { de estilo do final do século } \\
\text { XIX -2006 } \\
\text { Giselle Fernandes }\end{array}$ & $\begin{array}{l}\text { O ensino da pro- } \\
\text { dução de textos } \\
\text { na escola brasi- } \\
\text { leira por meio do } \\
\text { livro Manual de } \\
\text { Estilo, de V. Sá } \\
\text { de Menezes }\end{array}$ & $\begin{array}{l}\text { Jean Hébrard, Anne- } \\
\text { Marie Chartier, } \\
\text { André Chervel, } \\
\text { Circe Bittencourt, } \\
\text { Roberto Acízelo } \\
\text { de Souza, Mikhail } \\
\text { Bakhtin, Schneuwly } \\
\text { e Dolz e Jean-Michel } \\
\text { Adam } \\
\text { Pesquisa documental }\end{array}$ \\
\hline & $\begin{array}{l}\text { 19. A escola primária no Es- } \\
\text { tado do Pará }(1920-1940) \\
-2008 \\
\text { Maricilde Oliveira Coelho. }\end{array}$ & $\begin{array}{l}\text { A cultura da es- } \\
\text { cola primária no } \\
\text { Brasil/Pará }\end{array}$ & $\begin{array}{l}\text { Dominique Julia, } \\
\text { Raymond Williams e } \\
\text { Roger Chartier } \\
\\
\text { Pesquisa documental } \\
\text { Pesquisa narrativa } \\
\end{array}$ \\
\hline UFES & $\begin{array}{l}\text { 20. Encontro e desencon- } \\
\text { tros entre o mundo do texto } \\
\text { e o mundo dos sujeitos nas } \\
\text { práticas de leitura desenvol- } \\
\text { vida em escolas capixabas na } \\
\text { primeira república - } 2009 \\
\text { Maria Alayde Alcântara Sa- } \\
\text { lim. }\end{array}$ & $\begin{array}{l}\text { Práticas de lei- } \\
\text { turas desenvol- } \\
\text { vidas no Ginásio } \\
\text { do Espírito San- } \\
\text { to e na Escola } \\
\text { Normal Pedro } \\
\text { II, durante a Pri- } \\
\text { meira República }\end{array}$ & $\begin{array}{l}\text { Mar Bloch, Michel } \\
\text { de Certau, Carlos } \\
\text { Ginzburg e Roger } \\
\text { Chartier } \\
\text { Pesquisa documental } \\
\text { e Pesquisa narrativa }\end{array}$ \\
\hline
\end{tabular}

Fonte: Banco digital de teses da CAPES, da UFMG, da UNICAMP e da UNESPabr/2011

\subsection{Análise teórico-metodológica das teses}

\subsubsection{O foco metodológico}

Conforme se verifica no quadro 2, 14 teses apresentam o foco metodológico na pesquisa documental. Em termos percentuais, isso corresponde a $80 \%$ dos trabalhos. Por se tratar de estudos de natureza 
histórica, o corpus revela condições sociais e históricas do objeto pesquisado que, nos dados analisados, predominam documentos escritos, tais como: cartilhas, livros de leitura, memorial de leitura, correspondências, jornais, documentos oficiais prescritivos (leis, normas, ordens, decretos, circulares etc.), textos literários, manuais, revistas etc., os quais justificam a predominância da pesquisa documental.

Contudo, foi possível encontrar trabalhos com foco metodológico na pesquisa-ação, no estudo de caso etnográfico, na pesquisa autobiográfica, entre outros, que, por aparecer apenas um ou dois casos, não foram analisados.

\subsubsection{Os pressupostos teórico-metodológicos}

$\mathrm{Na}$ pesquisa, observou-se que as teses têm como principal orientação teórica os trabalhos desenvolvidos no campo da história cultural ${ }^{1} .90 \%$ das pesquisas estão inseridas no domínio das teorias críticas da educação, trazendo temáticas relacionadas a histórias de vida, cultura escolar, história das disciplinas escolares, história da leitura, história do livro e da literatura, história da educação etc.

A história cultural, em sua pluralidade, pode ser analisada a partir de três importantes teóricos: a) Carlo Ginzburg ${ }^{2}$, historiador e antropólogo italiano: com seu pioneirismo no estudo da micro-história, tem como foco de estudo a cultura popular; b) Edward Palmer Thompson, historiador britânico da concepção teórica marxista ${ }^{3}$ : trata dos movimentos sociais; e c) Roger Chartier ${ }^{4}$, historiador francês: estuda especialmente a história do livro e da leitura por meio dos conceitos de representação e apropriação. As concepções teórico-metodológicas de Chartier aparecem em $60 \%$ dos trabalhos ${ }^{5}$ e de Gunzburg em 5\%. Thompson sequer aparece

\footnotetext{
${ }^{1}$ Ver quadro 2.

${ }^{2}$ Fonte http://pt.wikipedia.org/wiki/Carlo_Ginzburg

${ }^{3}$ Fonte http://pt.wikipedia.org/wiki/Edward_Palmer_Thompson

${ }^{4}$ Dados extraídos do livro 'A história ou a leitura do tempo, de autoria de Roger Chartier.

${ }^{5}$ Não se levou em consideração os trabalhos nos quais não foi possível encontrar os pressupostos teórico-metodológicos.
} 
na orientação teórica, talvez porque este autor esteja vinculado, sobretudo, aos trabalhos voltados para a história social.

Segundo Chartier (2010, p. 15), a história tem a "tripla tarefa de convocar o passado, que já não está num discurso no presente; mostrar as competências do historiador, dono das fontes; e convencer o leitor". Segundo Pécora, ${ }^{6} \mathrm{O}$ campo da história das práticas da leitura possui três vias: a primeira de matriz eminentemente histórica em que levanta formas de leitura que não estão no presente, em que o corpus analisado diz respeito a atitudes antigas, práticas de leitura datadas; a segunda está relacionada à história das práticas da leitura, em que o autor se apropria do texto; e a última via diz respeito à observação e à descrição dos múltiplos empregos do termo 'leitura'. Essa matriz possibilita romper com a perspectiva tradicional da leitura que a concebe monolítica e homogênea. Diante do exposto, proceder-se-á à análise teórico-metodológica das teses.

De acordo com o gráfico 1, abaixo, as pesquisas se concentram, predominantemente, na UNICAMP, graças ao projeto acadêmico do Instituto de Estudos da Linguagem (IEL), intitulado 'Memória de Leitura $^{97}$, coordenado pelas professoras doutoras Marcias Azevedo Abreu ${ }^{8}$ e Marisa Pilbhert Lajolo9. O projeto é voltado para pesquisas sobre a história da leitura e do livro no Brasil, cujo objetivo é não só tornar acessível bibliografia, dados e fontes primárias aos pesquisadores da área, como também divulgar o resultado das pesquisas desenvolvidas pelos pesquisadores vinculados ao projeto.

O foco principal das pesquisas está relacionado a estudos que versam sobre sociedade, cultura, educação e crítica literária, orientados para a história da prática da leitura. Além dos estudos desenvolvidos por Roger Chartier, as teses também evocam outros teóricos do campo da história cultural, tais como: Michel de Certeau, Robert Darnton e Laurence Hallewell. Além desses, os trabalhos também apresentam autores relacionados a estudos sócio-históricos, como Vigotsky e Emília

${ }^{6}$ PÉCORA, Alcir. Introdução à edição brasileira. In. CHARTIER, 2009.

${ }^{7}$ Consultar o site http://www.unicamp.br/iel/memoria/

${ }^{8}$ Orientadora da tese 13: 'Impressões em preto e branco: história da leitura em Mato Grosso na segunda metade do século XIX (2008).

${ }^{9}$ Orientadora da tese 15: 'Infância, de Graciliano Ramos: uma história da formação do leitor no Brasil (2004). 
Ferreiro, e crítico-literários, tais como Afrânio Coutinho, Antônio Cândido e Salvatore D'Onofrio, todos articulados com o objeto estudado.

\section{Gráfico 1: teses defendidas nos Programas de Pós-graduação}

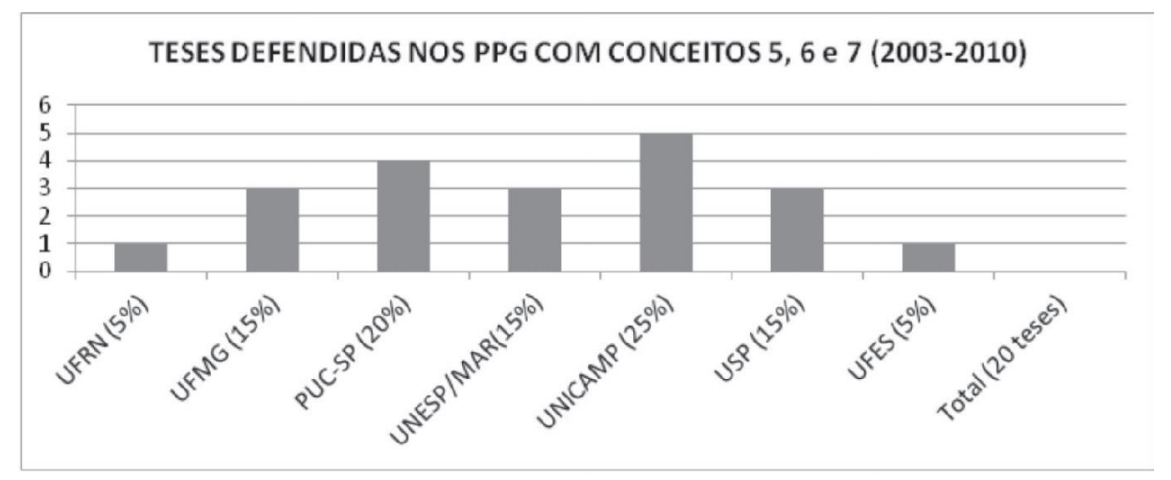

A segunda instituição que concentrou o maior número de pesquisas voltadas para o objeto pesquisado foi a PUC-SP, reunindo $20 \%$ dos trabalhos. Das quatro teses analisadas, duas são da área de língua portuguesa/linguística ${ }^{10}$ e uma da área de história social ${ }^{11}$. Portanto, observa-se que nesta instituição, os trabalhos cuja orientação teórica diz respeito à história cultural/práticas de leitura transitam por programas de pós-graduação em língua portuguesa (estudos descritivos e historiográficos), história e educação.

As teses provenientes dos programas de pós-graduação em língua portuguesa/linguística, além de tomarem como referência Roger Chartier, apoiam-se também em teóricos da área da linguagem/leitura, tais como Roland Barthes e Maria Lúcia Martins.

A tese vinculada ao programa de pós-graduação em história social, embora a leitura do resumo ${ }^{12}$ não indique referencial teórico para ser analisado, apresenta uma particularidade que vale a pena mencionar: o trabalho defende uma concepção pós-crítica da educação. Em termos

\footnotetext{
${ }^{10}$ Ver quadro 2, teses 5 e 6.

${ }^{11}$ Ver quadro 2, tese 7.

${ }^{12}$ Não foi possível ter acesso ao trabalho completo.
} 
teórico-metodológicos, o resumo do trabalho mostra que este faz "relações entre a história das mulheres e de gênero com estudos da memória social e da história da leitura", tratando do "particular, do específico e do diferente na sociedade."13

A UFMG, a UNESP/MAR e a USP reúnem, cada uma delas, $15 \%$ das pesquisas. O referencial teórico predominante nas teses versa sobre: a) história cultural: Roger Chartier, Michel e Certeau; b) cultura escolar e história das disciplinas escolares: Viñao Frago, Dominique Julia, André Chervel e Jean Hébrard; e d) língua e linguagem: Vigotsky e Bakhtin.

Das nove teses encontradas nas três instituições de ensino superior (IES) acima, três serão analisadas por terem uma relação estreita com a pesquisa inicial da autora deste artigo: uma da $\mathrm{UFMG}^{14}$, e duas da USP ${ }^{15}$.

A tese Cultura escolar, práticas e produções dos grupos escolares em MG (1891-1918), publicada em 2004, está vinculada ao programa de pós-graduação em educação da UFMG, cujo objetivo é compreender o processo de produção da escola primária em Minas Gerais, no período de 1891 a 1918. A orientação teórico-metodológica está baseada nos conceitos de estratégia e tática, de Michel de Certeau, articulados com as noções de cultura escolar e escolarização, introduzidas por Viñao Frago, Dominique Julia e Faria Filho. A tese investiga o panorama cultural que emergiu na escola, em Minas Gerais, cujos atores não apenas reproduzem as imposições pedagógicas regulamentares, mas também se apropriam desses modelos. Por meio das orientações teóricometodológicas escolhidas, buscou-se conhecer as práticas culturais do cotidiano escolar.

A tese Os paradeiros da escola primária pública paulista 1922-2002: representações sobre o tempo, os espaços e os métodos, publicada em 2005, é proveniente do programa de pós-graduação em história social da USP. Apesar da impossibilidade de acesso ao trabalho

\footnotetext{
${ }^{13}$ Texto transcrito do resumo da tese.

${ }^{14}$ Ver quadro 2, tese 3.

${ }^{15}$ Ver quadro 2, teses 17 e 19.
} 
completo e de informações insuficientes contidas no resumo, por meio da investigação, procura-se "identificar o lugar da escola [em frente dos] processos urbanos sofridos pela cidade de São Paulo e a arquitetura escolar desenvolvida por diferentes instituições ao longo dessa periodização"16. Este trabalho faz parte da linha de pesquisa 'História e cultura' e parece inscrever-se na perspectiva da cultura escolar.

A última tese analisada é A escola primária no Estado do Pará (1920-1940), de 2008. O trabalho está vinculado ao programa de pósgraduação em educação da USP. Analisa a cultura da escola primária no Brasil, em particular no Pará, apresentando um panorama do quadro social, político, cultural e econômico da sociedade brasileira. Do ponto de vista teórico-metodológico, inscreve-se nas concepções de cultura escolar, introduzidas por Dominique Julia, e da história cultural, Roger Chartier.

As três teses analisadas, ao ter como foco a escola primária brasileira sob a perspectiva da história cultural, são importantes para os pesquisadores que investigam sobre a história das práticas da leitura. Todas as teses se inscrevem na primeira matriz teórica introduzida por Pécora, de caráter fundamentalmente histórico, viés diferente do que será seguido pela autora, mas em nada contraditório a ele.

É importante enfatizar que a terceira tese trará valiosas contribuições para a forma como a autora deste trabalho tratará o objeto atual da sua pesquisa, qual seja, 'livros escolares de leitura do início do século XX' adotados na Amazônia. Essa tese traz indicações de livros produzidos no Estado do Pará que podem servir de corpus para a pesquisa.

\section{Considerações finais}

Este trabalho tencionou fazer um breve levantamento das teses desenvolvidas sobre a 'história das práticas da leitura no Brasil', cujo objetivo foi investigar como esse objeto vem sendo tratado do ponto de vista teórico-metodológico. A pesquisa não foi exaustiva. Pode-se dizer até que o número de teses coletadas não representa muito do que

\footnotetext{
${ }^{16}$ Texto transcrito do resumo da tese.
} 
vem sendo produzido no Brasil no domínio da história das práticas de leitura. A dificuldade de se encontrar um número maior de teses se deu em razão de o banco de teses da CAPES encontrar-se desatualizado, e também por não ter sido feita uma pesquisa minuciosa em todos os bancos de teses das 21 IES, com conceito CAPES 5, 6 e 7, em razão da exiguidade do tempo.

Por meio dos dados levantados, porém, foi possível perceber que, do ponto de vista teórico-metodológico, as teses analisadas se inscrevem no domínio da história cultural, transitando, sobretudo, pela história das práticas da leitura, foco principal, e pela história das escolas e das práticas escolares, representadas predominantemente por Roger Chartier e Dominique Julia, respectivamente. Os trabalhos, em sua maioria, estão ancorados na pesquisa documental pela natureza histórica que sustentam cujo corpus para análise está construído por meio de documentos escritos. Ainda pela característica histórica, 90\% das teses são de concepção crítica da educação.

Mesmo com um número reduzido de teses, pode-se perceber também que os trabalhos transitam por diferentes áreas do conhecimento, entre as quais está Língua Portuguesa/Linguística e História Social, havendo, portanto, uma articulação entre a história/ historiografia da língua portuguesa, a história da educação brasileira e a história social e um diálogo profícuo entre os principais teóricos dessas áreas.

No que diz respeito especificamente às concepções que orientam o campo da história das práticas da leitura, nos trabalhos analisados prevalece a matriz de cunho eminentemente histórico, cujo pesquisador analisa formas de leitura que se inscrevem no passado, mas que podem trazer informações importantes capazes de desvendar questões do presente. A análise focaliza em atitudes antigas, práticas de leitura datadas.

A pesquisa foi esclarecedora, no sentido de revelar os movimentos teórico-metodológicos que têm orientado as pesquisas sobre história da leitura no Brasil. Os dados têm especial relevância para os pesquisadores que pretendem debruçar-se sobre os aspectos histórico-culturais de 
um determinado objeto, uma vez que revela que matriz(es) teórica(s) $\operatorname{precisa}(m)$ de especial atenção.

Espera-se que essa breve investigação contribua para a delimitação de diferentes pesquisas que ainda possam surgir dentro dos estudos voltados para a história da leitura e das práticas escolares.

\section{REFERÊNCIAS}

AMBROGI, Ingrid Hötte. Os paradeiros da escola primária pública paulistana 1922-2002: representações sobre o tempo, os espaços e os métodos. Tese de Doutorado. 277p. Paulo: Universidade de São Paulo, 2005.

CAPES. Banco de teses. Disponível: <http://capesdw.capes.gov.br/ capesdw/. > Acesso: 3, 4, 5, 6, 7, 8/04/2011.

CHARTIER, Roger. A história ou a leitura do tempo. $2^{\text {a }}$ ed. Belo Horizonte: Autêntica, 2010.

COELHO, Maricilde Oliveira. A escola primária no Estado do Pará (1920-1940). Tese de Doutorado. 205p. São Paulo: Universidade de São Paulo, 2008.

GINZBURG, Carlo. Wikipedia. Biblioteca digital. Disponível em: $<$ http://pt.wikipedia.org/wiki/Carlo_Ginzburg. $>$ Acesso: 7/05/2011.

GONÇALVES, Irlen Antônio. Cultura escolar: práticas e produção dos grupos escolares em Minas Gerais (1989-1918). Tese de Doutorado. 283p. Belo Horizonte: UFMG, 2004.

PÉCORA, Alcir. Introdução à edição brasileira. In: CHARTIER, Roger (Org.). Práticas de leitura. $4^{a}$ ed. São Paulo: Estação liberdade, 2009.

THOMPSON, Edward P. Wikipedia. Biblioteca digital. Disponível: <http://pt.wikipedia.org/wiki/Edward_Palmer_Thompson.> Acesso: 14/05/ 2011.

UFMG. Biblioteca digital. Disponível: <http://www.

bibliotecadigital.ufmg.br/dspace/simple-search?query $=$ memoria s+da+leitura\&start=110 > Acesso: 10, 11, 12, 13/04/2011. 
UNESP. Cathedra - Biblioteca Digital de Teses e Dissertações. Disponível < http://unesp.br/cgb/conteudo.php?conteudo=562> Acesso: 14, 15, 17/04/2011.

UNICAMP. Projeto Memória da Leitura. Disponível: <http://www. unicamp.br/iel/memoria/> Acesso: 7/05/2011.

UNICAMP. Biblioteca digital. Disponível < http://www.

bibliotecadigital.unicamp.br/document/list.php?tid=7>. Acesso: 17, 18, 19/04/2011. 